\title{
A Novel PCM1-PDGFRB Fusion in a Patient with a Chronic Myeloproliferative Neoplasm and an ins $(8 ; 5)$
}

\author{
Muna Ghazzawi ${ }^{a}$ b Varun Mehrac Marcin Knut ${ }^{a}$ Loretta Brown ${ }^{c}$ \\ William Tapper ${ }^{a} \quad$ Andrew Chase $^{a, b}$ Hugues de Lavallade ${ }^{c}$ \\ Nicholas C.P. Cross ${ }^{a}$ b \\ ${ }^{a}$ Faculty of Medicine, University of Southampton, Southampton, ${ }^{b}$ Wessex Regional Genetics Laboratory, \\ Salisbury NHS Foundation Trust, Salisbury, and ' Department of Haematology, King's College Hospital, London, UK
}

A 54-year-old male patient presented in December 2008 with raised eosinophils on a routine full blood count. The white cell count was $10.3 \times 10^{9} / \mathrm{L}$ with hemoglobin $13.6 \mathrm{~g} / \mathrm{dL}$, platelets $154 \times 10^{9} / \mathrm{L}$, and eosinophils $1.4 \times$ $10^{9} / \mathrm{L}$. He was otherwise asymptomatic. BCR-ABL1 and FIPIL1-PDGFRA were both negative and his cytogenetics was reported as del(5)(q22q31) in 10 of 30 metaphases. Based on the above findings, he was formally diagnosed with myeloproliferative neoplasms, unclassified (MPN$\mathrm{U})$ with chromosome 5 abnormalities and eosinophilia. He was initially treated with low-dose dasatinib (the physician's choice), with a good hematological response and rapid resolution of the peripheral blood eosinophilia, but the treatment was discontinued after 10 months due to recurrent, symptomatic pleural effusions.

In 2013, nearly 5 years after the initial diagnosis, the patient continued to have persistent but asymptomatic mild eosinophilia off-therapy with otherwise normal blood counts. Cytogenetics was repeated and showed a $46, \mathrm{XY}$,ins $(8 ; 5)(\mathrm{p} 23 ; \mathrm{q} 33 \mathrm{q} 35)$ in all 30 metaphases analyzed. Retrospective analysis of the original diagnostic sample revealed the same abnormality, which had originally been misinterpreted due to poor-quality metaphases. Fluorescence in situ hybridization (FISH) analysis using PDGFRB breakapart probes (Cytocell, Cambridge,
$\mathrm{UK}$ ) confirmed disruption of $P D G F R B$ in both the original and follow-up samples. Based on this new finding and the reported efficacy of imatinib in PDGFRB-rearranged MPN [1, 2], the patient was treated with low-dose imatinib (200 mg daily) in July 2013. This was well tolerated and within 3 months of therapy, a repeat bone marrow assessment showed complete morphological and cytogenetic remission including FISH negativity for the PDG$F R B$ rearrangement. Ongoing assessments indicated continuing morphological and cytogenetic remission whilst being maintained on low-dose imatinib, with FISH negativity in January 2015 and July 2016.

In order to have a marker for more sensitive minimal residual disease analysis, we retrospectively sought to identify the putative $P D G F R B$ fusion partner using archived frozen cells taken at the time of initial diagnosis. Despite only being able to extract poor-quality RNA from the sample (RNA integrity number $<5$ ), we performed RNA-seq analysis. PolyA+ RNA extraction, library preparation, and 100-bp paired-end sequencing was performed with multiplexing for a minimum of 75 million reads per sample using an Illumina HiSeq 2000. Bowtie, TopHat, and TopHat-Fusion were used to align reads, resolve splice junctions, and identify and filter potential tyrosine kinase fusions, as previously described [3]. On

\section{KARGER}

(c) 2017 S. Karger AG, Basel

E-Mail karger@karger.com

www.karger.com/aha
Nicholas C.P. Cross

Wessex Regional Genetics Laboratory,

Salisbury NHS Foundation Trust, Salisbury District Hospital

Salisbury, SP2 8BJ (UK)

E-Mail ncpc@soton.ac.uk 
Fig. 1. $P C M 1-P D G F R B$ fusion. a Fusion junction of the chimeric PCM1-PDGFRB gene. b RT-PCR analysis: PCM1-PDGFRB was amplified from patient cDNA (E3419) but not negative control cases (E1180, E1181) using the primers PCM-AF ( $5^{\prime}-\mathrm{AC}$ A C A G A C T A C T T G A G A C A G A G GGC- $3^{\prime}$ ) in PCM1 exon 25 and PDGFRBAR (5'-GCTCCGACATAAGGGCTTGCTTC- $3^{\prime}$ ) in PDGFRB exon 14 . a, c MRD analysis. PCM1-PDGFRB CDNA was amplified by nested PCR for 30 cycles, each round using the primers $\mathrm{PCM}-\mathrm{AF}$ plus PDGFRB-AR in the first step, followed by reamplification with the primers PCM-DF (5' -TGCTGATAATGCTAGTGTCCT GTCT) in PCM1 exon 27 and PDGFRBDR (5' -TGATAAGGGAGATGATGGTGAGCAC- $3^{\prime}$ ) in PDGFRB exon 11 for the second step. c The resulting product of 134 bp was seen in dilutions of the ins $(8 ; 5)$ patient's presentation cDNA down to $10^{-3}$, but not in control samples or in blood or bone marrow samples taken 3 years after starting imatinib. b Confirmation of sample quality by amplification of normal $A B L 1$ cDNA using primers ABL $123 \mathrm{~F}\left(5^{\prime}\right.$ TGGAGATAACACCTTAAGCATTAACTAAAGGT- $\left.3^{\prime}\right)$ and ABL R (5'-GATGTAGTTGGTTGGGACCCA- $3^{\prime}$ ).

Fig. 2. Predicted structure of the PCM1PDGFR $\beta$ fusion protein. TM, transmembrane domain; TK, tyrosine kinase.

\section{PCM1 exon 27}

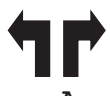

$\begin{array}{ccccccccccc}\text { A } & \text { T } & \text { D } & \text { D } & \text { L } & \text { A } & \text { L } & \text { P } & \text { F } & \text { K } & \text { V } \\ \text { gca } & \text { aca } & \text { gat } & \text { gat } & \text { cta } & \text { gCC } & \text { TTG } & \text { CCC } & \text { TTT } & \text { AAG } & \text { GTG } \\ \text { a } & & & & & & & & & & \end{array}$
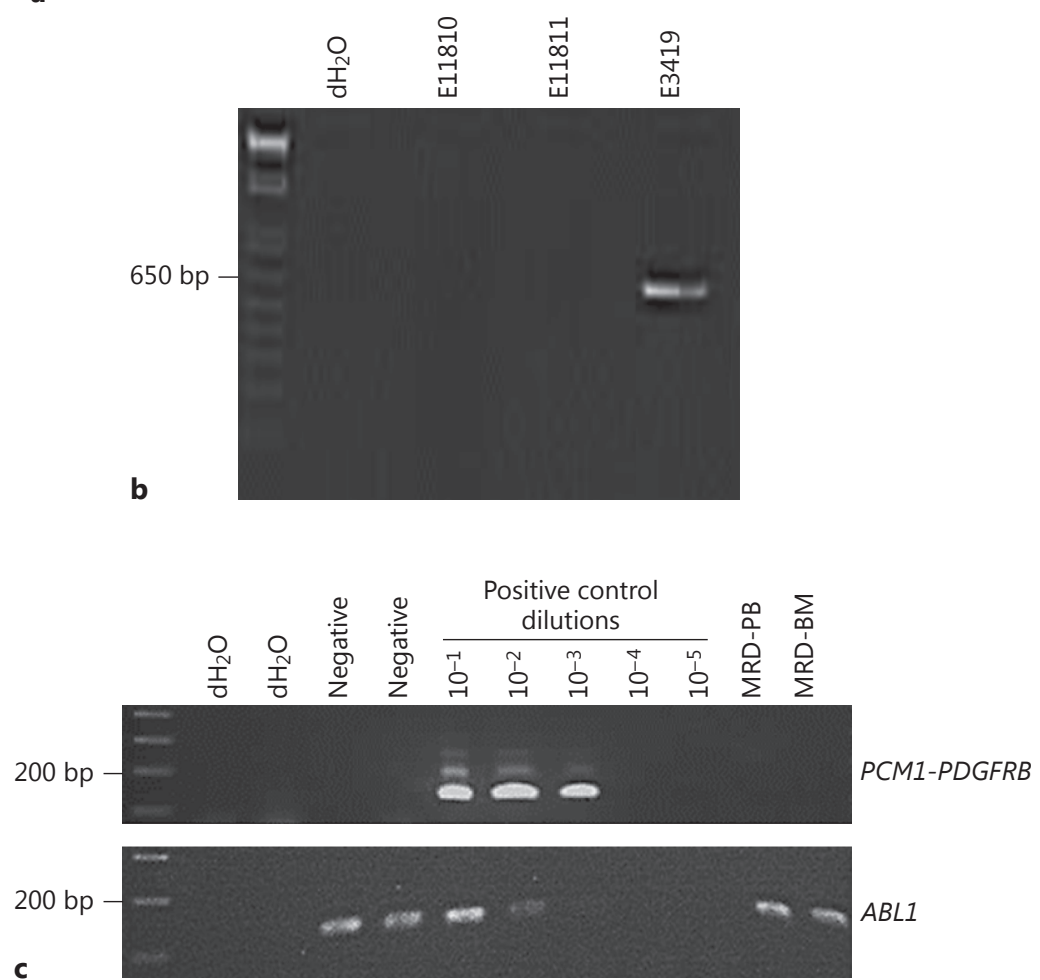

C

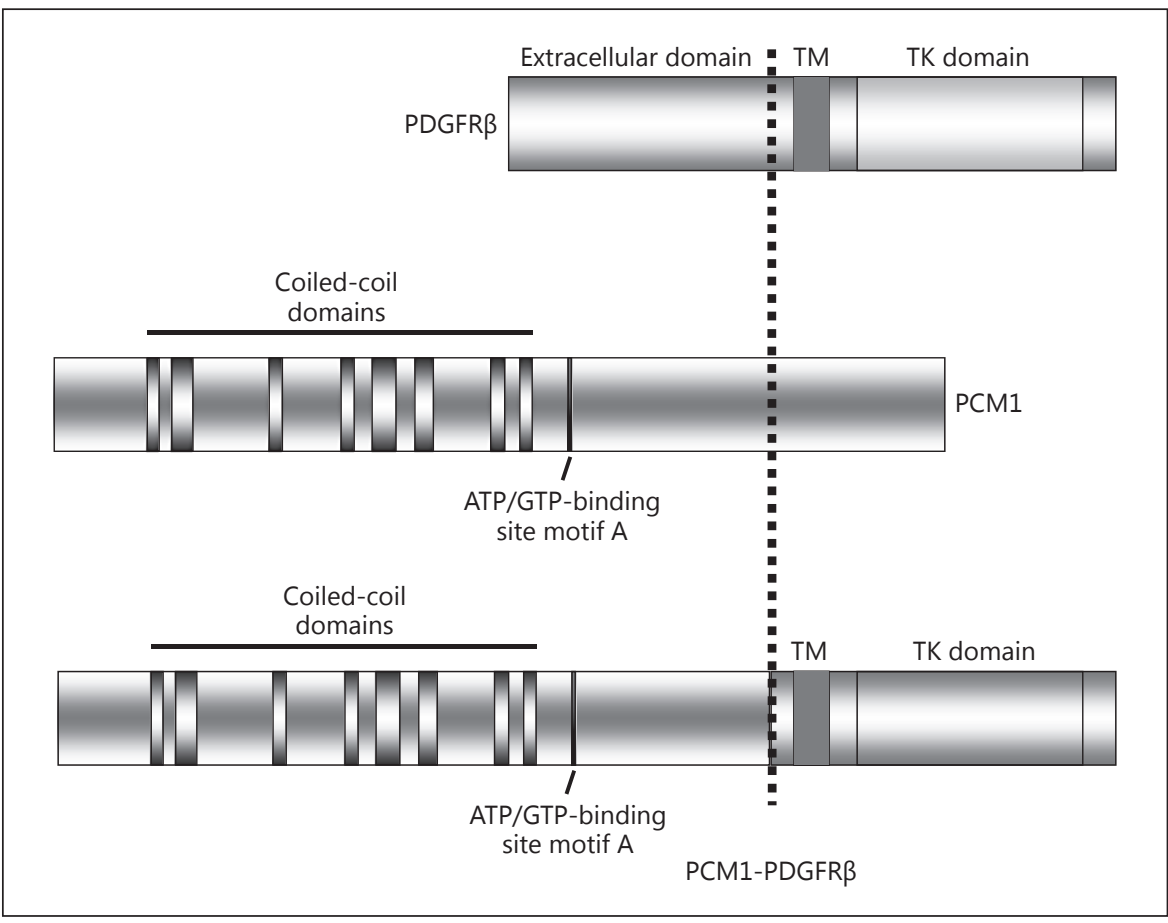


initial analysis no PDGFRB abnormalities were identified, but on relaxation of the filtering parameters, two breakpoint-spanning reads were identified with PCM1 fused to $P D G F R B$. Although this fusion has not been reported before, $P C M 1$ was a plausible candidate since it is located at $8 \mathrm{p} 22$ and fuses to the tyrosine kinase JAK2 in MPN with eosinophilia as a consequence of a recurrent $\mathrm{t}(8 ; 9)(\mathrm{p} 22 ; \mathrm{p} 24)[4]$. The PCM1-PDGFRB fusion was confirmed by RT-PCR and Sanger sequencing analysis, with $P C M 1$ exon 27 joined to $P D G F R B$ exon 11 , and thus preserving the reading frame (Fig. 1a, b). The fusion protein is predicted to retain the bulk of PCM1, including several coiled-coil domains and the entire transmembrane and cytoplasmic domains of PDGFR $\beta$ (Fig. 2).

Having identified and confirmed a PCM1-PDGFRB fusion in this case, we designed nested PCR primers for sensitive detection of minimal residual disease after therapy. Using serial dilutions of the (poor-quality presentation) cDNA in water, we found that the nested PCR was able to amplify the fusion down to a 1:1,000 dilution. We then tested blood and bone marrow samples taken from the patient 3 years after starting imatinib; residual PCM1PDGFRB mRNA was not detected in either sample (Fig. 1c).

It is known that signaling through PDGFRB plays an important role in mitogenesis, cytoskeletal rearrangements, and chemotaxis [5, 6]. Disruption of PDGFRB, normally located on chromosome $5 \mathrm{q} 33$, was first described as the consequence of the $t(5 ; 12)$, in which the $5^{\prime}$ end of ETV6 is juxtaposed to the $3^{\prime}$ end of PDGFRB [7]. Subsequently, many more translocations involving $5 \mathrm{q} 31-$ 33 have been identified, resulting in the identification of $>30$ distinct $P D G F R B$ fusion genes [8].

Pericentriolar material 1 (PCM1) encodes a component of centriolar satellites and is essential for the correct localization of several centrosomal proteins, and for anchoring microtubules to the centrosomes [9]. PCM1$P D G F R B$ and PCM1-JAK2 are thus further examples of fusions involving centrosome components, with potentially important functional consequences [10].

Many patients with $P D G F R B$ fusions achieve longterm molecular remission on imatinib therapy [2], and it appears that our case is no exception. Whether, as in chronic myeloid leukemia, some of these patients may be functionally cured and can safely stop treatment [11] remains to be seen. In the meantime, PCM1-PDGFRB should be added to the list of abnormalities associated with the WHO-defined subtype "myeloid/lymphoid neoplasms with eosinophilia and rearrangement of PDGFRA, PDGFRB, or FGFR1, or with PCM1-JAK2" [12].

\section{Disclosure Statement}

N.C.P.C. and H.d.L. have received honoraria from Novartis, Incyte, and Pfizer for advisory boards and speaking engagements. N.C.P.C. received research support from Novartis and H.d.L. received research support from Incyte.

\section{References}

1 Apperley JF, Gardembas M, Melo JV, RussellJones R, Bain BJ, Baxter EJ, Chase A, Chessells JM, Colombat M, Dearden CE, Dimitrijevic S, Mahon FX, Marin D, Nikolova Z, Olavarria E, Silberman S, Schultheis B, Cross NC, Goldman JM: Response to imatinib mesylate in patients with chronic myeloproliferative diseases with rearrangements of the platelet-derived growth factor receptor beta. N Engl J Med 2002;347:481-487.

2 Cheah CY, Burbury K, Apperley JF, Huguet F, Pitini V, Gardembas M, Ross DM, Forrest D, Genet P, Rousselot P, Patton N, Smith G, Dunbar CE, Ito S, Aguiar RC, Odenike O, Gimelfarb A, Cross NC, Seymour JF: Patients with myeloid malignancies bearing PDGFRB fusion genes achieve durable long-term remissions with imatinib. Blood 2014;123: 3574-3577.

3 Schwaab J, Knut M, Haferlach C, Metzgeroth G, Horny HP, Chase A, Tapper W, Score J, Waghorn K, Naumann N, Jawhar M, Fabarius
A, Hofmann WK, Cross NC, Reiter A: Limited duration of complete remission on ruxolitinib in myeloid neoplasms with PCM1$J A K 2$ and $B C R-J A K 2$ fusion genes. Ann $\mathrm{He}-$ matol 2015;94:233-238.

4 Reiter A, Walz C, Watmore A, Schoch C, Blau I, Schlegelberger B, Berger U, Telford N, Aruliah S, Yin JA, Vanstraelen D, Barker HF, Taylor PC, O’Driscoll A, Benedetti F, Rudolph C, Kolb HJ, Hochhaus A, Hehlmann R, Chase A, Cross NC: The $\mathrm{t}(8 ; 9)(\mathrm{p} 22 ; \mathrm{p} 24)$ is a recurrent abnormality in chronic and acute leukemia that fuses PCM1 to JAK2. Cancer Res 2005;65: 2662-2667.

5 Bergsten E, Uutela M, Li X, Pietras K, Ostman A, Heldin CH, Alitalo K, Eriksson U: PDGF$\mathrm{D}$ is a specific, protease-activated ligand for the PDGF $\beta$-receptor. Nat Cell Biol 2001;3: 512-516.

6 Jones AV, Cross NC: Oncogenic derivatives of platelet-derived growth factor receptors. Cell Mol Life Sci 2004;61:2912-2923.
7 Golub TR, Barker GF, Lovett M, Gilliland DG: Fusion of PDGF receptor beta to a novel ets-like gene, tel, in chronic myelomonocytic leukemia with $\mathrm{t}(5 ; 12)$ chromosomal translocation. Cell 1994;77:307-316.

8 Reiter A, Gotlib J: Myeloid neoplasms with eosinophilia. Blood 2017;129:704-714.

9 Hori A, Toda T: Regulation of centriolar satellite integrity and its physiology. Cell Mol Life Sci 2017;74:213-29.

10 Delaval B, Lelièvre H, Birnbaum D: Myeloproliferative disorders: the centrosome connection. Leukemia 2005;19:1739-1744.

11 Mahon FX: Discontinuation of TKI therapy and "functional" cure for CML. Best Pract Res Clin Haematol 2016;29:308-313.

12 Arber DA, Orazi A, Hasserjian R, Thiele J, Borowitz MJ, Le Beau MM, Bloomfield CD, Cazzola M, Vardiman JW: The 2016 revision to the World Health Organization classification of myeloid neoplasms and acute leukemia. Blood 2016;127:2391-2405. 